\title{
Ralstonia solanacearum $\triangle$ PGI-1 Strain KZR-5 Is Affected in Growth, Response to Cold Stress and Invasion of Tomato
}

\author{
Patricia Stevens • Leonard Simon van Overbeek • \\ Jan Dirk van Elsas
}

Received: 18 April 2010 /Accepted: 19 July 2010 /Published online: 18 August 2010

(C) The Author(s) 2010. This article is published with open access at Springerlink.com

\begin{abstract}
The survival and persistence of Ralstonia solanacearum biovar 2 in temperate climates is still poorly understood. To assess whether genomic variants of the organism show adaptation to local conditions, we compared the behaviour of environmental strain KZR-5, which underwent a deletion of the $17.6 \mathrm{~kb}$ genomic island PGI-1, with that of environmental strain KZR-1 and potato-derived strains 1609 and 715. PGI-1 harbours two genes of potential ecological relevance, i.e. one encoding a hypothetical protein with a RelA/SpoT domain and one a putative cellobiohydrolase. We thus assessed bacterial fate under conditions of amino acid starvation, during growth, upon incubation at low temperature and invasion of tomato plants. In contrast to the other strains, environmental strain KZR-5 did not grow on media that induce amino acid starvation. In addition, its maximum growth rate at $28^{\circ} \mathrm{C}$ in rich medium was signifi-
\end{abstract}

\section{P. Stevens}

Department of Microbial Ecology, Centre for Ecological and Evolutionary Studies (CEES), University of Groningen, P.O. Box 14, 9759 AA Haren, The Netherlands

\section{S. van Overbeek}

Plant Research International,

P.O. Box 16, 6700 AA Wageningen, The Netherlands

J. D. van Elsas

Department of Microbial Ecology, Centre for Ecological and Evolutionary Studies (CEES), University of Groningen, P.O. Box 14, 9750 AA Haren, The Netherlands

J. D. van Elsas $(\square)$

Department of Microbial Ecology, CEES,

University of Groningen,

Kerklaan 30,

9751 NN Haren, The Netherlands

e-mail: j.d.van.elsas@rug.nl cantly reduced. On the other hand, long-term survival at $4^{\circ} \mathrm{C}$ was significantly enhanced as compared to that of strains 1609, 715 and KZR-1. Although strain KZR-5 showed growth rates (at $28^{\circ} \mathrm{C}$ ) in two different media, which were similar to those of strains 1609 and 715 , its ability to compete with these strains under these conditions was reduced. In singly inoculated tomato plants, no significant differences in invasiveness were observed among strains KZR-5, KZR-1, 1609 and 715. However, reduced competitiveness of strain KZR-5 was found in experiments on tomato plant colonisation and wilting when using 1:1 or 5:1 mixtures of strains. The potential role of PGI-1 in plant invasion, response to stress and growth in competition at high and moderate temperatures is discussed.

\section{Introduction}

Ralstonia solanacearum biovar (bv) 2 is the causative agent of bacterial wilt of potato (Solanum tuberosum). In The Netherlands, it has appeared as from the mid-1990s and several outbreaks of the disease, potato brown rot, have been recorded in that period. Despite the strict quarantine measures that have been taken since then, the bacterium can still be found in Dutch local waterways, in surface water, ditch sediment as well as in the weed Solanum dulcamara (bittersweet) [11, 26, 35]. This strongly suggests the establishment of $R$. solanacearum bv2 in Dutch freshwater habitats. Because the organism is of tropical origin and supposedly non-endemic in Northwest Europe, it is generally assumed that the isolates found in these European ecosystems originated from the same ancestral (tropical) source. Indeed, amplified fragment length polymorphism (AFLP) analyses have revealed that the genomes of $R$. solanacearum bv2 strains obtained from different European 
countries (like France, the UK and The Netherlands) were very similar in comparison with those of isolates from elsewhere in the world [18, 19, 33]. However, some degree of genetic variation among European strains was found to exist, as determined by pulsed field gel electrophoresis with rare-cutting restriction enzymes and AFLP [26, 33]

Studies on the survival of $R$. solanacearum bv2 under local (oligotrophic) conditions in field soils, ditches and canals have been published [2, 34, 35]. From these studies, the conditions that affect the soil- and waterborne nature of $R$. solanacearum bv2 in The Netherlands, and its persistence in these open environments, have become evident. The survival strategies used by the organism might include physiological responses leading to reductions in cell size, entry of (part of) the population into the viable-but-nonculturable state and the formation of filamentous cells and cell aggregation [2]). Although factors such as light, low or high $\mathrm{pH}$, soil type, and the presence of an indigenous microbiota all can influence the survival of the organism, temperature seems to have an overriding impact on survival in temperate climates $[1,34,35]$. Low temperatures can have a dual effect on the survival of $R$. solanacearum bv2. First, the organism might become injured upon this stress [36], and second (on the positive side), predation or competition from the indigenous microorganisms may be reduced [1]. We hypothesised that our environmental $R$. solanacearum bv2 strains might have adapted their genomic make-up to the selective forces prevailing in the novel habitat. Thus, key organismal properties that allow survival under stress conditions (low temperature and low nutrient availability) or plant host invasion may have changed. Thus, it is important to investigate to what extent the genomes of the environmental $R$. solanacearum strains did diverge and how this divergence affected their fitness under specific (temperate climate) conditions.

A previous work in our laboratory revealed genetic differences between several strains that were isolated from Dutch local waterways and bittersweet plants growing at the edges of these waterways [26]. A thorough genetic analysis then showed that the genome of one of these strains, denoted KZR-5, harbors a deletion of $17.6 \mathrm{~kb}$, denoted putative genomic island 1 (PGI-1) [25]. The island encodes a total of 13 open reading frames (ORFs). Among these ORFs was a putative cellobiohydrolase $(\operatorname{cbh} A)$ gene as well as a gene encoding a protein with a conserved RelA/SpoT domain.

In Escherichia coli, the functioning of two homologous enzymes, i.e. the RelA and SpoT proteins, mediate the synthesis of hyperphosphorylated guanosine nucleotide, (p) ppGpp, which acts as a nutritional alarmone [6]. The two proteins regulate the levels of (p)ppGpp in the cell in response to amino acid and/or carbon starvation and are necessary in balancing the cell's nutritional capability and survival under stress conditions [6]. From a range of studies $[5,7,17,27,37]$, it has become clear that (p)ppGpp acts as a global regulator during the adaptation of bacteria to different environmental conditions, including low temperature, different eukaryotic hosts (pathogenesis and symbiosis) and in respect of bacterial multicellular behaviour $[4,24]$. In addition, the functioning of RelA and/or SpoT is often pleiotrophic, can differ between species and is dependent on the conditions used. Unlike Gram-negative bacteria, such as E. coli, many bacteria harbour single genes for RelA/SpoT-like enzymes that function in both degradation as well as synthesis of (p)ppGpp [16]. Recently, another class of (p)ppGpp synthetases (small alarmone synthetases, SASs) has been identified in Bacillus subtilis [17] and Streptococcus mutans [13], but their exact function is unknown.

To understand the putative function of PGI- 1 and the possible effect of the loss of the RelA/SpoT domain protein in $\triangle$ PGI-1 strain KZR-5, we investigated whether this strain is affected, as compared to potato strains 1609,715 and environmental strain KZR-1, in its response to amino acid starvation, to low temperature and upon growth in nutrient-poor and nutrient-rich media. Because PGI-1 also encodes a $c b h \mathrm{~A}$ gene, we hypothesised that the PGI-1 deletion might also incur a change in behaviour of KZR-5 in its invasion of susceptible host plants. We therefore looked at the strain's ability to degrade carboxymethylcellulose (CMC), which is typically performed by proteins with endoglucanase activity (EgII in $R$. solanacearum) and the ability to hydrolyse methylbelliferyl cellobiose (MUC), performed by proteins with exoglucanase activity (CbhA in $R$. solanacearum). Finally, to assess whether the lack of PGI-1 influenced the organism at any stage of interaction with the plant, we compared the virulence of strain KZR-5 to that of strains 1609,715 and KZR-1 in single-strain as well as joint inoculation tomato invasion assays.

\section{Methods}

\section{Bacterial Strains and Media}

The bacterial strains used in this study are listed in Table 1 . Strains 1609 (The Netherlands) and 715 (Bangladesh) were derived from diseased potato plants. Strains KZR-1 (PGI-1+) and KZR-5 ( $\triangle$ PGI-1) were isolated from bittersweet growing in a Dutch local waterway [26]. All four $R$. solanacearum strains belong to bv2, which is a highly homogenous group of organisms. They produce similar BOX-PCR patterns and have identical 16S rRNA gene sequences [26]. The E. coli $\mathrm{BW} 25113$ wild-type and $\Delta$ relA strain of the Keio collection $[3,8]$ were kindly provided by Dr. Javier Pozueta Romero of the Agrobiotechnology 
Table 1 Bacterial strains used in this study

\begin{tabular}{|c|c|c|}
\hline Strain & Relevant genotype & Reference \\
\hline \multicolumn{3}{|l|}{ R. solanacearum } \\
\hline 1609 & Pulsotype A & {$[35]$} \\
\hline 715 & Pulsotype A & [31] \\
\hline KZR-1 & Pulsotype A & {$[26]$} \\
\hline KZR-5 & Pulsotype $\mathrm{C}$, deletion of $17.6 \mathrm{~kb}$ putative genomic island, PGI-1 & {$[25,26]$} \\
\hline \multicolumn{3}{|c|}{ 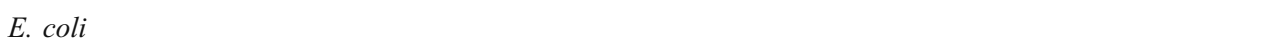 } \\
\hline BW 25113 wild type & Wild-type K12 derivative & {$[3]$} \\
\hline BW $25113 \Delta$ relA & $\Delta$ relA from the Keio collection & [3] \\
\hline
\end{tabular}

Institute in Navarra, Spain. Bacterial strains were maintained at $-80^{\circ} \mathrm{C}$ in $0.1 \times$ TSBS medium [ $10 \%$ strength trypticase soy broth (Becton Dickinson and Company, Sparks, MD, USA), $0.1 \%$ sucrose; $\mathrm{pH}$ 7.2] containing $20 \%$ glycerol. E. coli strains were routinely grown in Luria broth at $37^{\circ} \mathrm{C}$. For routine analyses of $R$. solanacearum, strains were grown at $28^{\circ} \mathrm{C}$ with shaking in liquid $0.1 \times \mathrm{TSBS}$. For growth rate determinations, we also used $\mathrm{BG}$ (Bacto peptone, $10 \mathrm{~g}$; yeast extract, $1 \mathrm{~g}$; casamino acids, $1 \mathrm{~g}$; glucose, $5 \mathrm{~g} ; \mathrm{H}_{2} \mathrm{O}, 1 \mathrm{~L}$; $\mathrm{pH}$ 7.2) and M63 [Amresco, Solon, USA; containing $\left(\mathrm{NH}_{4}\right)$ $2 \mathrm{SO}_{4}, 2 \mathrm{~g} ; \mathrm{KH}_{2} \mathrm{PO}_{4}, 13.6 \mathrm{~g} ; \mathrm{FeSO}_{4} \cdot 7 \mathrm{H}_{2} \mathrm{O}, 0.5 \mathrm{mg}$; Milli-Q water, $1 \mathrm{~L} ; \mathrm{pH}$ 7.0] media. These media were autoclaved for $15 \mathrm{~min}$ at $121^{\circ} \mathrm{C}$, after which filter-sterilised dissolved $\mathrm{MgSO}_{4}$ $(1 \mathrm{mM})$ and glucose $(0.1 \%)$ were added. Solid growth media contained 1.5\% (w/v) purified agar (Duchefa, Haarlem, The Netherlands) and were supplemented with $0.05 \%(w / v)$ 1,3,5tetrazolium chloride (TZC) (Sigma, St. Louis, USA).

\section{AT and SMG Growth Tests}

Because (p)ppGpp-deficient mutants often exhibit multiple amino acid auxotrophy on minimal medium, we tested the growth of strains 1609,715 , KZR-1 and KZR-5 on plates containing 3-amino-1,2,4-triazole (AT), which blocks histidine biosynthesis, and on plates containing serine, methionine and glycine (SMG) as described [21, 32]. The $R$. solanacearum strains were streaked onto AT medium (M63 agar with $15 \mathrm{mM} \mathrm{AT,} 5 \mu \mathrm{g} / \mathrm{mL}$ thiamine and $100 \mu \mathrm{g} / \mathrm{mL}$ methionine) or SMG medium (M63 agar with $100 \mu \mathrm{g} / \mathrm{ml}$ each of serine, methionine and glycine) plates and incubated overnight at 28 and $37^{\circ} \mathrm{C}$. As controls, E. coli strain BW25113 and its $\Delta$ relA derivative were used (Table 1).

\section{Qualitative Enzyme Assays}

The production of exoglucanases (EC 3.2.1.9) by $R$. solanacearum strains was assessed by growing cells for $2-5$ days at $28^{\circ} \mathrm{C}$ on M63 agar plates containing $0.4 \%$ glucose and $100 \mu \mathrm{M}$ 4-methyl umbelliferyl- $\beta$-D-cellobiose (MUC, Sigma, St. Louis, USA ) and subsequent examination of the growth under UV light. The appearance of fluorescence under UV light would indicate the cleavage of the cellobiose with the production of 4-methylumbelliferone [30]. Carboxymethyl cellulase activity of the type typically displayed by endo-1,4- $\beta$-D-glucanases (EC 3.2.1.4) was determined by growing cells for 2-7 days at $28^{\circ} \mathrm{C}$ on $\mathrm{M} 9$ agar plates containing $2.5 \mathrm{~g} / \mathrm{L}$ of $\mathrm{CMC}$ (Sigma Aldrich, USA). When sizeable colonies appeared, the plates were stained with $0.1 \%$ Congo red solution [29] for $20 \mathrm{~min}$ and rinsed with $10 \mathrm{~mL}$ of $1 \mathrm{M} \mathrm{NaCl}$ for $10 \mathrm{~min}$. The appearance of a halo around the inoculation spot indicated endoglucanase activity.

\section{Survival in Sterile Demineralised Water}

The effects of two temperatures, 4 and $20^{\circ} \mathrm{C}$, on the survival over time of $R$. solanacearum bv2 strains 1609, 715, KZR-1 and KZR-5 were assessed in sterile water microcosms. Exponentially grown and washed cells (twice with Milli-Q purified sterile water) were transferred to triplicate $100-\mathrm{mL}$ bottles containing $20 \mathrm{~mL}$ of sterile ultrapure Milli-Q water, establishing final population densities of between log 6.6 and $\log 7.1$ cells per millilitre. Flasks were incubated without shaking, in the dark, at the appropriate temperatures, i.e. 4 and $20^{\circ} \mathrm{C}$. At set times, $1-\mathrm{mL}$ samples were aseptically removed from each flask. Aliquots were serially diluted in sterile Milli-Q water and plated $(100 \mu \mathrm{L})$ onto $0.1 \times$ TSBS agar plates. Plates were incubated for $2-5$ days at $28^{\circ} \mathrm{C}$, after which colonies were counted and the numbers of colony forming units per millilitre $(\mathrm{CFU} / \mathrm{mL})$ calculated.

\section{Determination of Growth Rates}

The growth rates of strains 1609, 715 and KZR-5 were measured in cultures growing in $0.1 \times$ TSBS, BG and M63 media. For growth in $0.1 \times$ TSBS and M63 media, aliquots $(20 \mu \mathrm{L})$ of overnight cultures grown at $28^{\circ} \mathrm{C}$ with shaking were aseptically added to flasks containing $20 \mathrm{~mL}$ of fresh medium, after which the resulting cultures were incubated at $28^{\circ} \mathrm{C}$ (as well as at $16^{\circ} \mathrm{C}$ for $0.1 \times$ TSBS medium) until the $\mathrm{OD}_{660}$ values reached $0.8-1.2$. For growth in $\mathrm{BG}$ medium, flasks were inoculated with cells from BGT plates using a sterile loop. Samples were taken at set times (depending on the medium used) and the $\mathrm{OD}_{660}$ values 
determined. In addition, in the growth experiments in BG and $0.1 \times$ TSBS at $16^{\circ} \mathrm{C}$, the number of $\mathrm{CFU}$ was determined by dilution plating on BGT plates. The maximum growth rates for each strain and each growth medium were determined from the growth dynamics over the whole time course. Maximum growth rate was calculated using the formula $\mu_{\max }=\ln \left(N_{2} / N_{1}\right) /\left(t_{2}-t_{1}\right)$, where $N_{2}$ is the cell concentration at $t=2$ and $N_{1}$ is the cell concentration at $t=1$.

\section{Competition Experiments}

As subtle differences in the growth rates of strains 1609, 715 and KZR-5 might remain undetected when growing in single cultures, we tested the competitive abilities of strain KZR-5 against 1609 and 715 in $0.1 \times$ TSBS at 16 and $28^{\circ} \mathrm{C}$ in mixed cultures (KZR-5/1609 and KZR-5/715). The mixes initially received equal numbers of each strain. To prepare starter cultures for these experiments, cells were grown overnight, with shaking, at the relevant temperature in $0.1 \times$ TSBS until the $\mathrm{OD}_{660}$ values reached $0.7-1.1$. They were then washed twice with sterile Milli-Q water. To obtain mixed cultures containing totals of $1.0 \times 10^{6} \mathrm{CFU} / \mathrm{mL}$, appropriate volumes of washed cells were transferred to flasks containing $20 \mathrm{~mL}$ of $0.1 \times$ TSBS (start $\mathrm{OD}_{660}, \sim 0.05$ ). These cultures were dilution-plated onto $0.1 \times$ TSBS plates containing TZC to affirm the ratio between the inoculated strains (set at 1:1), as explained in the following.

To enable the discrimination of strains, we used colony morphology as the criterion in combination with PCRbased colony screens for confirmation. The colonies obtained for strains 1609, 715 and KZR-5/KZR-1 differed morphologically, and the colony morphologies were stable, on $0.1 \times$ TSBS plates containing TZC, as follows. Colonies of strains 1609 and 715 were distinguished from those of strain KZR-5 on the basis of their clearly reddish and dry colony morphology, as opposed to the whitish and glossy appearance of KZR-5. In addition, the colonies of strains KZR-5 and KZR-1 were $\sim 1.5$-fold larger than those of the other strains, as they visibly produced more extracellular polysaccharide. To support/confirm the colony-morphologybased screenings for strains KZR-5 and 1609/715, a colony PCR screen (system ps-6 [25]) was used, which amplifies the PGI-1 genomic region that is present in strains 1609 and 715 but absent from strain KZR-5. Thus, the small reddish colonies typical for strains 1609 and 715 (as well as the KZR-1 colonies) generated the predicted $559 \mathrm{bp}$ fragment using this PCR system, while amplification on the basis of the large white colonies typical for strain KZR-5 yielded no product.

For the colony PCR analysis, colony material was picked with a sterilised toothpick and transferred to $100 \mu \mathrm{L}$ Milli-Q water, after which it was strongly mixed. One microlitre of this suspension, 10-fold diluted or not, was then used as the template source for PCR analysis $(25 \mu \mathrm{L}$ volume). For PCR amplification, we used the GeneAmp PCR System 9700 (Applied Biosystems, Foster City, CA, USA). Standard PCR reaction mixtures contained $1 \times$ PCR buffer $(1.5 \mathrm{mM} \mathrm{MgCl}$, $10 \mathrm{mM}$ Tris and $50 \mathrm{mM} \mathrm{KCl}$, Roche Applied Science, Basel, Switzerland), $2.5 \mathrm{mM} \mathrm{MgCl} 2,10 \%$ dimethyl sulfoxide, $200 \mu \mathrm{M}$ each deoxynucleotide, $0.2 \mu \mathrm{M}$ of each primer and $20 \mathrm{U} / \mathrm{mL}$ Taq DNA polymerase (Roche Applied Science, Basel, Switzerland). The cycling program was as follows: a denaturation step at $96^{\circ} \mathrm{C}$ for $7 \mathrm{~min}$, followed by 34 cycles of: $96^{\circ} \mathrm{C}, 40 \mathrm{~s} ; 60^{\circ} \mathrm{C}, 45 \mathrm{~s} ; 72^{\circ} \mathrm{C}, 40 \mathrm{~s}$, finalised by an extension step of $72^{\circ} \mathrm{C}$ for $5 \mathrm{~min}$. PCR products were analysed by electrophoresis on $0.8 \%$ agarose gels (Roche Diagnostics, Mannheim, Germany).

To determine the competitive fitness of the strains at $28^{\circ} \mathrm{C}$, the mixed cultures were grown overnight or until reaching an $\mathrm{OD}_{660}$ of 0.9 (after approximately seven generations) and dilution-plated at regular times onto BGT plates. To assess competition at $16^{\circ} \mathrm{C}$, serial batch cultures were used. The first cultures were established by transferring $10 \mu \mathrm{l}$ of each grown culture $\left(\mathrm{OD}_{660}\right.$ between 0.5 and 0.8 , after approximately 2 days) to flasks containing $20 \mathrm{~mL}$ fresh $0.1 \times$ TSBS. After four transfers (approximately 40 generations), aliquots from the cultures were dilution-plated onto BGT plates, which was followed by quantification of the CFUs of the competing strains as above.

\section{Tomato Invasion Assays}

To assess the behaviour of environmental strains KZR-5 and KZR-1 and of potato strains 1609 and 715 when in association with tomato plants, at least 12 3-4-week-old tomato plants per strain/treatment in soil in pots were inoculated as described [26].

\section{Single-Strain Inoculations}

Strains KZR-5, 1609 and 715 were introduced into the soil adjacent to plants in replicated separate pots at cell densities of either $10^{8}$ or $10^{5} \mathrm{CFU} / \mathrm{mL}$ (estimated density per gram soil was $5 \times 10^{6}$ or $5 \times 10^{3}$ ), after which plants were kept under a day/ night regime of $26^{\circ} \mathrm{C}$ (day, $\left.14 \mathrm{~h}\right) / 21^{\circ} \mathrm{C}$ (night, $10 \mathrm{~h}$ ). Control plants received sterile Milli-Q water instead of bacterial cells. Plant disease development was then scored at 7, 14 and 21 days following inoculation using a disease matrix ranging from 0 (no wilting symptoms) to 4 (all leaves wilted) [38].

\section{Mixed-Strain Inoculation}

Mixed suspensions of strain KZR-5 with the comparator strains 1609,715 and KZR-1 (all in 1:1 ratios) were used to inoculate the plant/soil systems in a fashion similar to the foregoing. In addition, a ratio of 5:1 was tested for the mixture KZR-5/715. The strain mixtures were prepared by adding appropriate cell 
numbers of these strains to $250 \mathrm{~mL}$ Milli-Q water, establishing total cell densities of approximately $10^{7} \mathrm{CFU} / \mathrm{mL}$.

To enumerate the $R$. solanacearum cells from the soil and tomato plants, we used cell extraction/dilution plating procedures, using modified semi-selective SMSA plates [10]. Thus, 2 days after inoculation, $0.5 \mathrm{~g}$ soil samples were taken (in triplicate), shaken in $0.01 \mathrm{M}$ phosphate buffer $(\mathrm{pH} 7.0)$ for $1 \mathrm{~h}$ and dilution-plated on SMSA. At 10 and 21 days post-inoculation, cuttings of $1 \mathrm{~cm}$ of the lower stem parts (approximately $4 \mathrm{~cm}$ above the soil) were removed from three plants and shaken in $2 \mathrm{~mL} 0.01 \mathrm{M}$ phosphate buffer for up to $2 \mathrm{~h}$ at room temperature. After this, the resulting suspensions were dilution-plated onto modified SMSA plates. All plates were incubated at $28^{\circ} \mathrm{C}$ for $2-$ 5 days, after which they were scored.

Following plate incubation, the ratios between strains KZR-5 and 1609 as well as 715 were determined on the basis of the morphology of colonies, supported by PCR screens as described before. To determine the ratio's for the strain KZR-5/KZR-1 mixes, we applied the ps-6 PCR system [25] consistently on 24-48 randomly selected colonies for each replicate sample.

\section{Statistical Treatment of the Data}

All experiments were executed in triplicate, except the growth rate and long-term survival (at $20^{\circ} \mathrm{C}$ ) experiments, which had duplicate systems. All CFU counts were logtransformed, after which mean values and standard deviations were calculated on the basis of log-transformed values. To describe the decline in CFU counts over time at $4^{\circ} \mathrm{C}$, the log-transformed data were fitted to a modified logistic function by non-linear regression (Gauss-Newton method [23]), and the decline rate values were compared using Student's $t$ test (one-tailed distribution). For comparison of long-term survival values of the strains at $20^{\circ} \mathrm{C}$, growth rates $\left(\mu_{\max }\right)$ and competition experiments, we used two-tailed Student's $t$ tests on the replicates. To determine the significance of the differences in long-term survival, the decline rate (slope) of each individual replicate was compared across strains. For the competition experiments, the ratio of strains at the beginning of the experiment was compared to that at the end of the experiment. Student's $t$ tests were judged to be significant at $P<0.05$.

\section{Results and Discussion}

Determination of the Phenotype of the $\triangle$ PGI-1 Mutant Strain KZR-5

PGI-1 Encodes a Putative Small Alarmone Synthetase The genomic island PGI-1 was found to possess a putative gene
(RSIPO_04909) that encodes a 486 amino acid (AA) long protein with a conserved (p)ppGpp synthetase catalytic domain (spanning AA 42 to 234, i.e. roughly 200 AA in size). This domain has also been found in the E. coli RelA and SpoT proteins. These proteins mediate the synthesis of the alarmone (p)ppGpp, which is relevant in the response of the organism to amino acid and/or carbon starvation. As many Gram-negative bacteria possess single copies of the relA and spoT gene, we examined the $R$. solanacearum bv2 strain 1609 genome for it. This analysis revealed that one copy of each gene was present in strain 1609. These genes probably encode proteins homologous to the E. coli RelA and SpoT proteins (RSIPO_01119, RelA and RSIPO_ 01943, SpoT). These proteins consistently possessed, next to the so-called RelA/SpoT domains, other conserved domains, namely HD (thought to be involved in (p)ppGpp degradation), TGS (conserved ATP/GTP-binding domain) and ACT (conserved ATP/GTP-binding and GTPbinding domain) (Fig. 1a) [5]. In contrast, the PGI-1-borne R. solanacearum RelA/SpoT domain protein was smaller than the RelA/ SpoT enzymes (486 versus 676-793 AA) and, clearly, did not possess the associated HD, TGS and ACT domains (Fig. 1a).

BLAST-P searches using the PGI-1 borne RelA/SpoT domain as the query revealed highest similarity to proteins of Rhizobium etli (identity, 49\%; E value, 2e-38), Bacillus cereus (identity, 46\%; $E$ value, $2 \mathrm{e}-31$ ), Streptomyces viridochromogenes (identity, 50\%; $E$ value, 8e-31) and Exiguobacterium sp. (43\%, $E$ value, 2e-30). A subsequent comparison of the deduced amino acid sequence of the PGI-1-encoded protein (RSIPO_04909) with those of the homologues identified by NCBI BLAST-P and those (SAS proteins) of B. subtilis (YjbM and YwaC) and S. mutans (RelP and RelQ) showed clear conservation of several amino acids at fixed positions (Fig. 1b). Specifically, 10 residues were fully conserved between the aligned sequences (Fig. 1b). Of these, four had previously been shown to be functionally significant in Streptococcus dysgalactiae [12]. Another 11 residues were fully conserved among the SAS proteins of B. subtilis and $S$. mutans, the PGI-1-borne RelA/SpoT domain protein and its closest homologues, but not with the RelA and SpoT proteins of $E$. coli or with their counterparts in $R$. solanacearum.

Surprisingly, phylogenetic analyses of the aligned (partial) amino acid sequences then revealed that the PGI-1 RelA/SpoT protein as well as the identified homologues of $R$. etli, B. cereus, S. viridochromogenes and Exiguobacterium were more closely related to the SAS proteins of $B$. subtilis and $S$. mutans than to either one of its own RelA or SpoT proteins (Fig. 1c). On this basis, we hypothesised that the PGI-1-encoded RelA/SpoT domain protein encodes a putative SAS-like protein, which-by analogy to the situation in B. subtilis-may be involved in the biosynthesis or level control of an alarmone with a mode of 
a

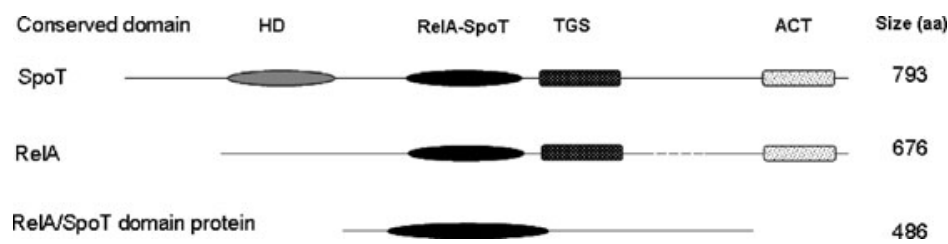

b

\begin{tabular}{|c|c|c|c|c|}
\hline & & I & & || \\
\hline RelA-E. coli & 225 & YYIEEFVGH & 275 & 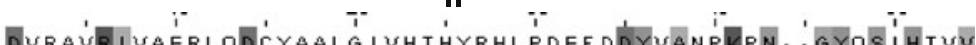 \\
\hline RelA-R. sol & 228 & $R E$ KF IGEA I AR & 278 & VIVDDIKDCYTVLGFVHHMWQPIPKEFDDYISRP \\
\hline SpoT-E. coli & 209 & RKEMIQKILSE & 259 & VIVNDSDTCYRVLGQMHSLYKPRPGRVKDYIAIP \\
\hline SpoT-R. sol & 281 & RREVVSRILEA & 331 & VVVETQMQCYMAVGALHSLYKPMPGKF KDYIAIP \\
\hline YjbM-B. sub & 46 & PVAS I LE & 72 & IMCQF VDDIQ I VKEMLFARKDFTVVDQRDYIAEH \\
\hline RelQ-S. mut & 43 & PIESIKE & 70 & I MVQF VDDVNDVLELLRQRKDMKVIQERDYINNL \\
\hline YwaC-B. sub & 58 & SFESIVN & 87 & DI AGVR I I CSF ISD I YNVVNVLKQHEDLRIVKVKDYIQTP \\
\hline RelP-S. mut & 47 & RIKTNESMIE & 76 & DA IG IR IVCGFVDD I YKMVAILKTLDGVNVYNEKDYIYNAKPN. GYRSYHLIL \\
\hline RSIPO_04909 & 53 & -AKDFDSFSE & 84 & $V \perp T Y V P R T V R D V E D V \perp R R E F N V D E R \perp D K D A . A \perp \perp G S G D \perp G Y K S \perp H F \perp V$ \\
\hline R. etli * & 3 & - AKN I ESFLN & 32 & I I TYTLKDLEKVDRF IVGNFD IVEKRDVGE - ERYKEGKFGYQS I HYLV \\
\hline S. vir & 44 & - VKTKGSTVR & 69 & I VTYFPNDVDRVAEVIRDEFL I DEDNSTDKRALLDADRFGYLSLHYVA \\
\hline Exi & 49 & - AKEADSLYA & 74 & DLAG IR IVTYFHDDVRAVAQ ILEDEFT I DREQS IDKSTLLDANEFGYLSVHYVV \\
\hline B. cer & 62 & D I ESFAKK & 86 & DLAG I R I TAYVESDVNKI CEVLEREFE I I QEHSVNKSA I LKYNEVGYRS I HYIA \\
\hline & & $\boldsymbol{\Delta} \boldsymbol{\Delta}$ & & $* * * *$ \\
\hline
\end{tabular}

III

\begin{tabular}{ll} 
RelA-E. coli & 335 \\
RelA-R. sol & 338 \\
SpoT-E. coli & 319 \\
SpoT-R. sol & 391 \\
YjbM-B. sub & 139 \\
RelQ-S. mut & 137 \\
YwaC-B. sub & 154 \\
RelP-S. mut & 147 \\
\hline RSIPO_04909 & 157 \\
\hline R. etli & 105 \\
S. vir & 143 \\
Exi & 148 \\
B. cer & 159 \\
\hline
\end{tabular}

\section{IV}

398 RSQVF́DDRVYVFTPKGDVVDL

410 KHTELDDHIYVLTPQARVIAL

380 KSDLFPDE IYVF TPEGR I VEL
452 KI DLFPDAVYVFTPKGEI RAL

170 KLRLQRASEAASRLDEEMSE

185 TDELKEAAE I AHYLDEKMLG I

178 AKELKRCADELASCDLSMQT I

188 KRRF VALAGLLEIADREFQS |

136 ERKF | ALAGLLEIADREFQA I

174 RRRFSRVAGLLEVADNEFQE I

179 KRSF SRVAGLLEIADSEF VN |

193

RRFALLAGQLELADREFDSI

\section{$\boldsymbol{\Delta}$}

RSIPO_04909

C

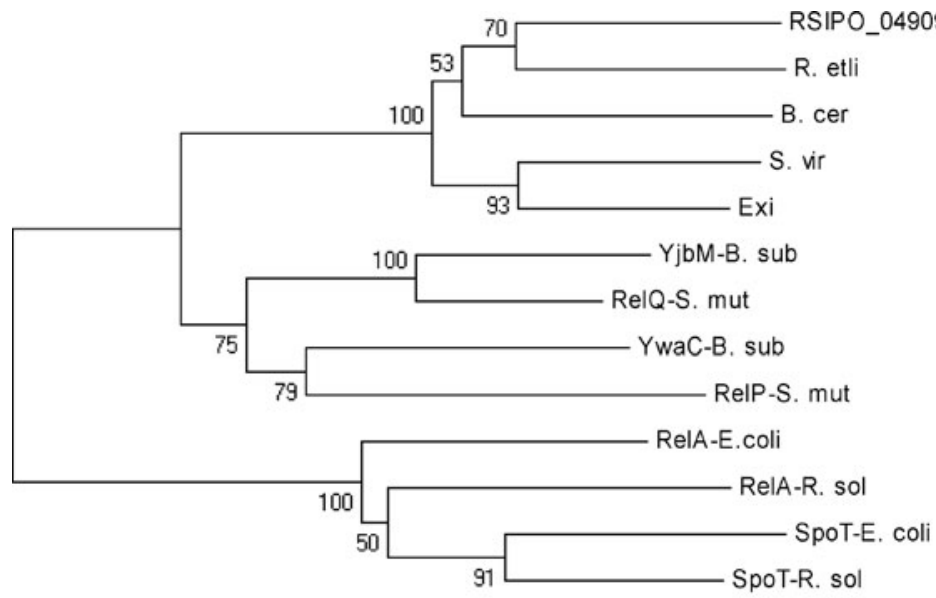

action distinct from that of the canonical RelA/SpoT homologues [17].

Moreover, the average $\mathrm{G}+\mathrm{C}$ content of the $R$. solanacearum PGI-1-borne relA/spoT gene was lower than the average $\mathrm{G}+\mathrm{C}$ content of its entire genome (i.e. 50\% versus 64\%), actually being on the order of the $\mathrm{G}+\mathrm{C}$ content of the genomes of the implicated Gram-positive species (40-50\%). Taking into account that the gene encoding the respective RelA/SpoT 
Figure 1 Comparison between SpoT, RelA and RelA/SpoT domain containing proteins. a Comparison of conserved domains found in SpoT, RelA and RelA/SpoT domain containing proteins. HD domain (possessing a conserved histidine $[\mathrm{H}]$ and aspartate [D] residue): possibly involved in (p)ppGpp degradation, only present in SpoT. TGS and ACT domains: conserved ATP/GTP-binding and GTP-binding domains, respectively [6]; found in SpoT as well as RelA. The RelA/ SpoT domain is shared by all three types of the RelA/SpoT-like proteins. b Alignment of the RelA/SpoT domain of SpoT and RelA of E. coli, R. solanacearum biovar 2, PGI-1 encoded RSIPO_04909, and eight related RelA/SpoT domain containing proteins using ClustalW. The position of the first amino acid of the four partial protein sequences (I-IV) is indicated and corresponds to the position of the first amino acid along the full-length protein. Stars Residues that are fully conserved among all sequences; triangles residues conserved among the SAS proteins of $B$. subtilis and $S$. mutans, the $R$. solanacearum RelA/SpoT domain protein and its closest homologues, but not with the RelA and SpoT proteins of $E$. coli and $R$. solanacearum; squares residues that were experimentally shown to be functionally significant in Streptococcus dysgalactiae [12]. E. coli, Eschericha coli; R. sol, Ralstonia solanacearum biovar 2; B. sub, Bacillus subtilis; S. mut, Streptococcus mutans; R. etli, Rhizobium etli; S. vir, Streptomyces viridochromogenes; Exi, Exiguobacterium; B. cer, Bacillus cereus. Asterisk For R. etli, a partial protein sequence was used due to unavailability of the full-length sequence. c Phylogenetic analysis of SpoT and RelA of E. coli and R. solanacearum biovar 2, together with the PGI-1-encoded RelA/SpoT domain protein, RSIPO_04909 and related RelA/SpoT domain containing proteins. The tree was conducted using Mega4 software [28], option neighbor joining, bootstrap 1,000 replicates and Poisson correction)

domain protein of $R$. solanacearum localises on genomic island PGI-1 [25] and that the degree of homology with the SAS genes was rather low, the gene (or island) might have been anciently transferred from Gram-positive lineages to $R$. solanacearum. The presence of a SAS-like gene in $R$. solanacearum bv2 and its putative involvement in the physiology of this organism, e.g. the stringent response, has so far not been described.

The PGI-1-Borne Putative RelA/SpoT Domain Protein May Confer a Phenotype on Strain KZR-5

$S M G$ and AT tests Comparison of the growth of E. coli BW25113 wild type, $E$. coli BW25113 $\Delta$ relA and $R$. solanacearum strains 1609, 715, KZR-1 and KZR-5 on SMG-containing plates revealed a clear growth defect for environmental strain KZR-5 when compared to strains 1609, 715 and KZR-1 (Table 2). The E. coli BW25113 wild type and $\Delta$ relA strains, which were used as controls, behaved as expected on SMG and AT, i.e. they showed fair growth of the wild-type strain and delayed growth of the $\Delta$ relA strain on these media. None of the $R$. solanacearum strains grew on plates containing AT, not even after 15 days of incubation. Thus, environmental strain KZR-5 showed a phenotype similar to that of $E$. coli $\Delta$ relA when grown on media containing excess $1-\mathrm{C}$ metabolites, whereas the other $R$. solanacearum strains did not.

Exo- and endoglucanase activity To assess whether strain KZR-5 is impaired in cellulose degradation, we tested its ability to utilise CMC and MUC. Overall, these tests, compared to the other strains, revealed that strain KZR-5 exhibited "normal" endoglucanase activity. Specifically, no differences were observed between the strains in the utilisation of $\mathrm{CMC}$, as judged by the sizes of the haloes of the corresponding colonies, following the procedure of Teather et al. [29] (Table 2). Unfortunately, we were not able to measure exoglucanase activity for any of the $R$. solanacearum strains, using MUC as a substrate, in a reproducible manner. Although the CbhA protein is secreted by $R$. solanacearum bv3 strain GMI1000 [14], the substrate it hydrolyses has never been demonstrated. It has been suggested that CbhA attacks the hemicellulose fraction of plant cell walls and that in vitro enzyme activity measurements can be hampered ( $\mathrm{T}$. Denny, personal communication).

Growth Rates of Strains 1609, 715 and KZR-5 in Different Media

The maximum exponential growth rates $\left(\mu_{\max }, \mathrm{h}^{-1}\right)$ of strains 1609, 715 and KZR-5 were assessed in different liquid growth media (Fig. 3). Overall, the growth rates of the three strains were lower when nutrient concentrations and/or temperature were lower (Fig. 2). In $0.1 \times$ TSBS at two temperatures, the three strains had similar growth rates, i.e. between $0.24 \pm 0.014$ and $0.27 \pm 0.012\left(\mu, \mathrm{h}^{-1}\right.$ ] at $28^{\circ} \mathrm{C}$ and between $0.11 \pm 0.05$ and $0.12 \pm 0.03\left(\mu, \mathrm{h}^{-1}\right]$ at $16^{\circ} \mathrm{C}$. The growth rates in $\mathrm{M} 63$ medium at $28^{\circ} \mathrm{C}$ were also similar between the three strains, i.e. between $0.043 \pm 0.001$ and $0.048 \pm 0.001\left(\mu, \mathrm{h}^{-1}\right)$. In $\mathrm{BG}$ medium at $28^{\circ} \mathrm{C}$, however, we found a significant difference in growth rate between strain KZR-5 and the comparator strains. The maximum growth rates of strains 1609 and 715 were similar (between $0.63 \pm 0.07$ and $0.69 \pm 0.07\left(\mu, \mathrm{h}^{-1}\right)$ while that of strain KZR-5 was significantly $(P<0.05)$ lowered $(0.39 \pm 0.03, \mu$, $\mathrm{h}^{-1}$; Fig. 2). Thus, strain KZR-5 showed growth rates similar to those of strains 1609 and 715 in nutrient-poor M63 medium, while on the other hand, it showed slower growth in nutrient-rich (BG) medium in comparison to the two other strains.

Competitiveness of $R$. solanacearum Strain KZR-5 Versus the Comparator Strains upon Growth in $0.1 \times$ TSBS at 16 and $28^{\circ} \mathrm{C}$

As the growth rate of environmental strain KZR-5 in $0.1 \times$ TSBS was similar to that of the potato strains 1609 and 715 (Fig. 2), we surmised that there might be subtle differences in their behaviour that can be evidenced in direct competition experiments. We thus used competition experiments in $0.1 \times$ TSBS at 28 as well as $16^{\circ} \mathrm{C}$ (Fig. 3). At both temperatures, the mixed cultures grew-as expected-in 
Table 2 Growth of strains on SMG, AT and CMC containing media and decline rates of $R$. solanacearum strains upon incubation in sterile Milli-Q water at 20 and $4^{\circ} \mathrm{C}$

\begin{tabular}{llllll}
\hline strain & SMG & AT & CMC & Decline rate, $20^{\circ} \mathrm{C}$ & Decline rate, $4^{\circ} \mathrm{C}$ \\
\hline E. coli BW 25113 wild type & + & + & nd & nd & nd \\
E. coli BW 25113 $\Delta$ relA & - & - & nd & nd & nd \\
R. solanacearum 1609 & + & - & + & $0.0029^{\mathrm{a}}$ & $0.051^{\mathrm{b}}$ \\
R. solanacearum 715 & + & - & + & $0.0026^{\mathrm{a}}$ & $0.055^{\mathrm{b}}$ \\
R. solanacearum KZR-1 & + & - & + & $0.0020^{\mathrm{a}}$ & $0.064^{\mathrm{b}}$ \\
R. solanacearum KZR-5 & - & - & + & $0.0020^{\mathrm{a}}$ & $0.034^{\mathrm{c}}$ \\
\hline
\end{tabular}

Statistical classes (superscripted $\mathrm{a}, \mathrm{b}$ and $\mathrm{c}$ ) are indicated. $P<0.05$

$n d$ not determined, $(+)$ growth on agar plates, $(-)$ no growth on agar plates

$16 \mathrm{~h}\left(28^{\circ} \mathrm{C}\right)$ and $50 \mathrm{~h}\left(16^{\circ} \mathrm{C}\right)$ to the maximum $\mathrm{OD}_{660}$ values of $0.8-1.2$. In all replicates of the experiments with the mixture KZR-5/1609, we noted a decrease in the relative abundance of strain KZR-5, i.e. an average 8-fold decrease at $28^{\circ} \mathrm{C}$ and a 5 -fold decrease at $16^{\circ} \mathrm{C}$. Competition of strain KZR-5 against strain 715 showed a similar result, although the relative decrease in abundance of strain KZR5 was lower (3-fold at $28^{\circ} \mathrm{C}$ and 2 -fold at $16^{\circ} \mathrm{C}$ ). The decreases in the relative abundances of strain KZR-5 versus strains 1609 and 715 were significant in both cases $(P<$ $0.05)$.

\section{Survival of $R$. solanacearum Strain KZR-5 Versus}

the Comparator Strains in Sterile Water at 20 and $4^{\circ} \mathrm{C}$

The survival, as CFUs, of strains 1609, 715, KZR-1 and KZR-5 in sterile Milli-Q water in still vials at 20 and $4{ }^{\circ} \mathrm{C}$ was followed over time. Upon incubation at $20^{\circ} \mathrm{C}$, the $\mathrm{CFU}$ numbers of strain KZR-5 showed an initial slight but progressive increase, from $\log 6.6$ to maximally $\log$ 6.9 CFU/mL until day 34. These numbers then remained

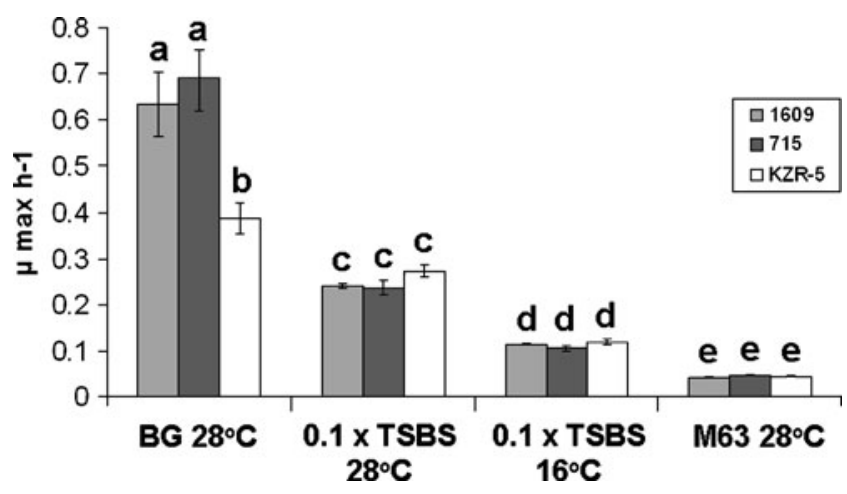

Figure 2 Maximum growth rate $\left(\mu_{\max } ; \mathrm{h}^{-1}\right)$ of strains KZR-5, 1609 and 715 at $28^{\circ} \mathrm{C}$ in BG, $0.1 \times$ TSBS and M63 and at $16^{\circ} \mathrm{C}$ in $0.1 \times$ TSBS. Maximum growth rate was determined for exponentially growing cells. Values are the average of at least two independent experiments. Statistical classes $(a, b, c, d$ and $e)$ are indicated $(P<0.05)$ roughly stable until day 105 . Upon extended incubation (28 months), the strain KZR-5 CFU numbers had decreased to between $\log 4.3$ and $\log 6.3 \mathrm{CFU} / \mathrm{mL}$. The dynamics of strains 1609,715 and KZR-1 resembled that of strain KZR5, with strain KZR-5 surviving slightly, although not significantly, better than the three comparator strains. However, the long-term survival of strain KZR-5 was more erratic ( $P$ values between 0.3 and 0.9$)$ than those of the other two strains (Table 2).

When the four strains were incubated in water at $4^{\circ} \mathrm{C}$, differences in population sizes started to emerge clearly after 30 days of incubation, with strain KZR-5 showing the highest survival upon further incubation. For all four strains, the CFU numbers declined until they became undetectable after 60-113 days (below the detection limit of $10 \mathrm{CFU} / \mathrm{mL}$; Fig. 4). The calculated decline rates over the whole time course were $0.034 \pm 0.014$ for strain KZR-5, $0.051 \pm 0.009$ for strain $1609,0.055 \pm 0.015$ for strain 715

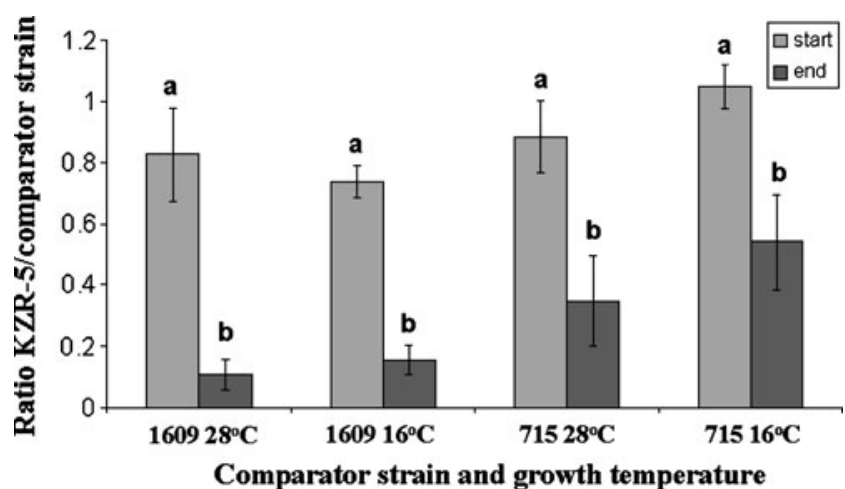

Figure 3 Competitiveness of $R$. solanacearum strain KZR-5 against strains 1609 and 715 in liquid $0.1 \times$ TSBS. The ratio between $\triangle$ PGI-1 strain (KZR-5) and the comparator strains (1609 or 715) is shown at the beginning of the experiment $(1: 1)$ and after growth in mixed cultures. For competition at $28^{\circ} \mathrm{C}$, the ratio between strains was determined from duplicate overnight cultures. For competition at $16^{\circ} \mathrm{C}$, the ratio between the strains was determined from (duplicate) batch cultures after four serial transfers. Statistical classes $(a$ and $b)$ are indicated; $P<0.05$ 


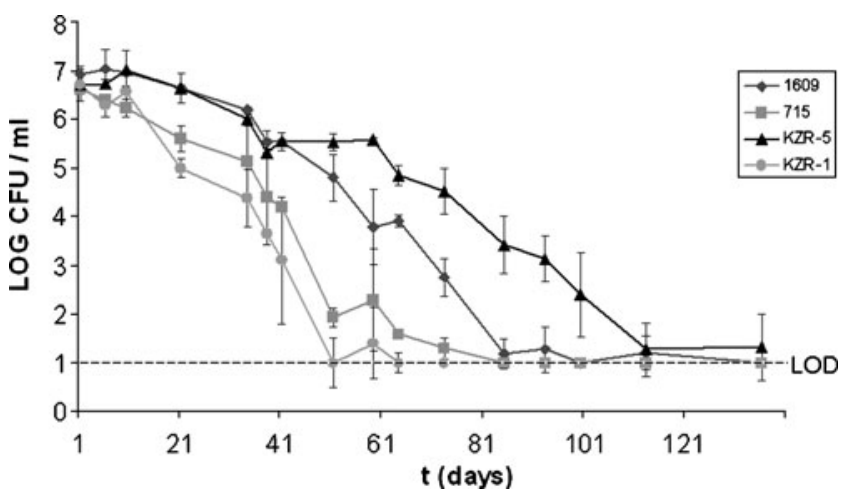

Figure 4 Survival of $R$. solanacearum strains 1609, 715, KZR-5 and KZR-1 at $4{ }^{\circ} \mathrm{C}$. The graph shows the colony forming unit enumerations on BG plates. Points represent the means of three replicate experiments. The limit of detection (LOD), $10 \mathrm{CFU} / \mathrm{mL}$, is indicated

and $0.064 \pm 0.005$ for strain KZR-1. The difference in the decline rates between strain KZR-5 and the three comparator strains over time was at the border of significance. Specifically, the $P$ value between KZR-5 and 1609 CFU numbers was 0.09 and between KZR-5 and 715 or KZR-1 was 0.05 .

Strain KZR-5 thus showed enhanced survival in water at low temperature $\left(4^{\circ} \mathrm{C}\right)$. On the other hand, we noted a decreased fitness upon growth in rich liquid medium. The rates of survival at low temperature and growth in rich media might indeed be related to cellular levels of (p)ppGpp, as shown for E. coli and Vibrio cholerae [7, 24]. This, thus, might provide support for a possible link between the behavioural changes that were observed and the lack of the PGI-1-encoded putative RelA/SpoT domain protein. However, the mutants described in the aforementioned studies had increased basal levels of (p)ppGpp due to the complete absence of the SpoT protein, which is not likely to be the case in the $\triangle$ PGI-1 strain KZR-5.

Competitiveness of $R$. solanacearum Strain KZR-5 upon Invasion of Tomato

To assess the virulence of environmental strain KZR-5 in comparison with those of 1609,715 and KZR-1, we determined the effects of high $\left(10^{8} \mathrm{CFU} / \mathrm{mL}\right)$ as well as low $\left(10^{5} \mathrm{CFU} / \mathrm{mL}\right)$ inocula over time. First, plants not receiving any inoculum remained $100 \%$ healthy over the course of the experiment. At both inoculum densities, strains KZR-5, KZR-1 and 715 induced wilting at similar rates. That is, full wilting was achieved in $100 \%$ of the plants within 14 days when using $10^{8} \mathrm{CFU} / \mathrm{mL}$, whereas between $67 \%$ and $72 \%$ of the plants showed symptoms when using $10^{5} \mathrm{CFU} / \mathrm{mL}$. In this experiment, plants inoculated with strain $1609\left(10^{8}\right.$ cells $\left./ \mathrm{mL}\right)$ wilted more slowly, and symptoms were less severe $(62 \%$ of the plants showed wilting at day 14 and $87 \%$ at day 21 . Using low inoculum densities, strain 1609 caused signs of wilting in half of the plants after 21 days, thus appearing as less virulent than the two other strains.

Given the fact that strain KZR-5 did not show reduced virulence as compared to strain 715 , we concluded their behaviour was grossly similar in uncompetitive situations. We then hypothesised that any differences in the rates of invasion and wilting might become apparent in competitive situations, i.e. under strain-to-strain competitive set-ups. Hence, we decided to perform joint KZR-5/715 and KZR5/1609 inoculation experiments. Strain 1609 was included to shed light on its apparently lowered virulence. To support our assumptions, we also tested the competitive ability of strain KZR-5 against environmental strain KZR1. The results of these experiments are shown in Fig. 5. At day 10 , plants treated with all strain mixes showed the development of disease symptoms (as from wilting stage 1), being the KZR-5/KZR-1 mixes most virulent (wilting stages 1 through 3). At day 21, disease development had progressed to wilting stages 3-4 for all mixes used, being the KZR-5/1609 mix less virulent than the KZR-5/715 or KZR-5/KZR-1 mixes. Only $50 \%$ of the plants inoculated with the KZR-5/1609 mix showed wilting symptoms after 21 days, while $100 \%$ of the plants that had been inoculated with the KZR-5/715 and KZR-5/KZR-1 mixes showed disease symptoms.

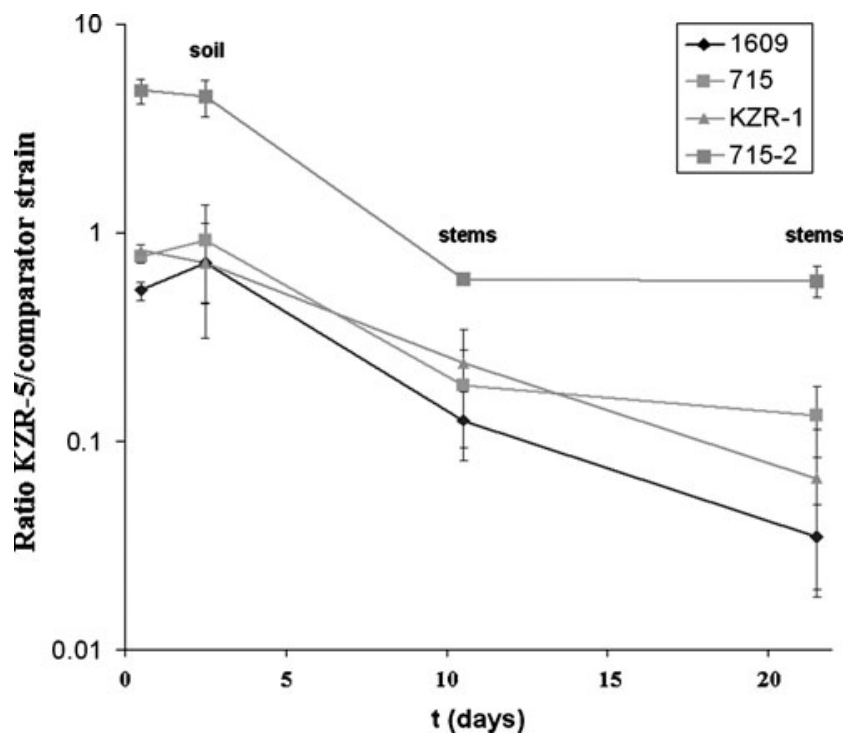

Figure 5 Competitiveness of $R$. solanacearum strain KZR-5 against strains 1609, 715 and KZR-1 upon invasion of tomato plants. The ratio between $\triangle$ PGI-1 strain KZR-5 and the comparator strains (1609, 715 and KZR-1) was determined by dilution plating on agar plates (BG or SMSA) at four time points. First, the ratio between strains was determined for the cell mixture used for inoculation of the plants on BG agar plates. Second, the ratio between strains in the soil was determined from CFUs on SMSA plates at day 2 (soil). Extraction of $R$. solanacearum from the tomato stems was done 10 and 21 days post-inoculation, and the ratio between strains was determined from CFU counts on SMSA plates (stems) 
Analysis of the mixed $R$. solanacearum populations in the soil at day 2 revealed that strains KZR-5, 1609, 715 and KZR-1 survived fairly well in the soil compartments, i.e. between $\log 5.0$ and $\log 6.0 \mathrm{CFU}$ were measured per gram soil for these strain mixes. Furthermore, for all mixes, the ratio between the two strains had remained roughly stable in the soil compartments, at $0.9 \pm 0.45$ (KZR-5/715) and $0.7 \pm 0.26$ (KZR-5/1609 as well as KZR-5/KZR-1) (Fig. 5).

In contrast, analysis of the ratio of strain KZR-5 versus competing strains 1609,715 and KZR-1 at 10 and 21 days after inoculation of the tomato plants consistently showed progressive declines of the prevalence of strain KZR-5 in the mixes (Fig. 5). Strikingly, this was also true for the KZR-5/1609 mix. Thus, although strain 1609 appeared as less virulent than strain KZR-5 in single inoculation experiments, it outcompeted strain KZR-5 in mixedinoculation experiments. The plants inoculated with these two strains showed an overall reduced rate of wilting, which is remarkable.

To strengthen the notion that environmental strain KZR5 was less competitive than its competitors in these plant systems, we tested its competitive ability against strain 715 using an initial excess of strain KZR-5, i.e. at an initial strain ratio of 5:1. Again, the relative proportion of strain KZR-5 in the mixes was quite stable in the soil, whereas it decreased progressively upon colonisation of the tomato stems (Fig. 5). The initial relative amount of strain KZR-5 was significantly higher than the relative amount found in the stems at day $21(P<0.05)$. Overall, we conclude that the relative numbers of strain KZR-5 in mixes with three counterpart strains remained roughly stable in the soil, whereas they decreased significantly during the process of invasion and colonisation of tomato plants. This decrease was independent of the ratio between the strains at the onset of the experiment (Fig. 5).

The reduced ability of environmental strain KZR-5 to colonise tomato plants may be the result of a reduced capacity to regulate or perform one or more of the steps that are required in the intricate processes that are involved in successful plant colonisation [22]. Overall, the plant invasion process is tightly regulated and requires a complex regulatory network of interacting gene products. Among the many genes that are up- and down-regulated are genes that encode cell-wall-degrading enzymes, such as $c b h A$. Although the gene product, CbhA, is not strictly essential for pathogenicity (the substrate it hydrolyses was never demonstrated), it was found to contribute to virulence on susceptible plants [14]. Possibly, such cell-wall-degrading enzymes play roles in the initial stages of plant colonisation as well as later, when cells have to penetrate the xylem vessels. For instance, EglI is required for efficient invasion of plant roots and colonisation of stems, where it might function in the degradation of cellulosic glucan compounds
$[9,20]$. Thus, although we were not able to demonstrate the absence of cellobiohydrolase activity in strain KZR-5, we did observe a (subtle) drop in competitiveness upon plant colonisation. It is tempting to speculate on the involvement of the PGI-1-located CbhA; however, other factors might also play a role. For instance, PGI-1 encodes a transcriptional regulator, which could affect numerous downstream processes. In addition, the function of the PGI-1-encoded hypothetical proteins is still unknown [25]. Furthermore, additional processes at the transcriptional or translational level might differ between the strains (regardless of PGI-1 being present or not).

Temperature regime might also affect both the growth and virulence of strains [15, 39]. Milling et al. [13] showed that the virulence of $R$. solanacearum bv2 strain UW551was similar to that of GMI1000 (bv3) and K60 (bv1) at $28^{\circ} \mathrm{C}$, while at $20^{\circ} \mathrm{C}$, strain UW551 revealed higher virulence [15]. In addition, RelA mutations can lead to decreased thermotolerance, as observed for E. coli [39]. Our competition experiments in tomato, in which strain KZR-5 revealed to be less competitive than strains 1609 , 715 and KZR-1, were performed at $26 / 21^{\circ} \mathrm{C}$ (day/night regime). On the basis of the foregoing, it is possible that strain KZR-5 has become less well equipped for plant invasion at the high-temperature regime used as opposed to lower temperatures.

Milling et al. [15] suggested that the survival of $R$. solanacearum bv2 in temperate climates is related to its interaction with host plants rather than to its persistence at low temperature in the open environment. However, in our study, environmental strain KZR-5 showed clearly enhanced survival at low temperature when compared to potato strains 1609 and 715 . In contrast, its colonisation efficiency on tomato host plants had decreased. However, whether the absence of genes for the SAS-like protein and the cellobiohydrolase indeed represents the key factor determining this altered phenotype of strain KZR-5 remained unsolved in this work and should be the target for future research. Thus, although we did not measure actual (p)ppGpp levels in this study, strain KZR-5 behaved like the $E$. coli (p)ppGpp mutant ( $\Delta$ relA). In E. coli, the effect seen on plates is due to isoleucine starvation. However, strain KZR-5 was able to grow normally (comparable to its siblings) on M63 minimal medium, which stood in contrast to the non-growth of $E$. coli $\Delta$ relA. The overall (growth/survival) behaviour of strain KZR-5 indicates that this strain is impaired in its response rate to specific nutritional conditions allowing growth, whereas it had enhanced tolerance to (low temperature) stress.

Acknowledgements We thank Sasha Semenov for the help with statistical analysis. We also thank Sytse Terpstra and Denny Kor for technical assistance with the competition experiments. 
Open Access This article is distributed under the terms of the Creative Commons Attribution Noncommercial License which permits any noncommercial use, distribution, and reproduction in any medium, provided the original author(s) and source are credited.

\section{References}

1. Álvarez B, López MM, Biosca EG (2007) Influence of native microbiota on survival of Ralstonia solanacearum phylotype II in river water microcosms. Appl Environ Microbiol 73:72107217

2. Álvarez B, López MM, Biosca EG (2008) Survival strategies and pathogenicity of Ralstonia solanacearum phylotype II subjected to prolonged starvation in environmental water microcosms. Microbiology 154(11):3590-3598

3. Tomoya B, Takeshi A, Miki H, et al (2006) Construction of Escherichia coli K-12 in fram, single-gene knockout mutants: the Keio collection. Mol Syst Biol 2:2006.0008

4. Braeken K, Moris M, Daniels R, Vanderleyden J, Michiels J (2006) New horizons for (p)ppGpp in bacterial and plant physiology. Trends Microbiol 14(1):45-54

5. Calderón-Flores A, Du Pont G, Huerta-Saquero A, MerchantLarios H, Servin-Gonzalez L, Duran S (2005) The stringent response is required for amino acid and nitrate utilization, nod factor regulation, nodulation, and nitrogen fixation in Rhizobium etli. J Bacteriol 187:5075-5083

6. Cashel M, Gentry DR, Hernandez VJ, Vinella D (1996) The stringent response. In: Escherichia coli and Salmonella: cellular and molecular biology. Washington: ASM Press, 1458-1496

7. Das B, Bhadra RK (2008) Molecular characterization of Vibrio cholerae Delta relA Delta spoT double mutants. Arch Microbiol 189:227-238

8. Datsenko KA, Wanner BL (2000) One-step inactivation of chromosomal genes in Escherichia coli K-12 using PCR products. Proc Natl Acad Sci USA 97:6640-6645

9. Denny TP, Carney BF, Schell MA (1990) Inactivation of multiple virulence genes reduces the ability of Pseudomonas solanacearum to cause wilt symptoms. Mol Plant-Microbe Interact 3:293-300

10. Elphinstone JG, Hennessy J, Wilson JK, Stead DE (1996) Sensitivity of different methods for the detection of Pseudomonas solanacearum (Smith) Smith in potato tuber extracts. Bull OEPP 26:663-678

11. Granada GA, Sequira L (1983) Survival of Pseudomonas solanacearum in soil, rhizosphere and plant roots. Can J Microbiol 29:433-440

12. Hogg T, Mechold U, Malke H, Cashel M, Hilgenfeld R (2004) Conformational antagonism between opposing active sites in a bifunctional Re1A/SpoT homolog modulates (p)ppGpp metabolism during the stringent response1. Cell 117(1):57-68

13. Lemos JA, Lin VK, Nascimento MM, Abranches J, Burne RA (2007) Three gene products govern (p)ppGpp production by Streptococcus mutans1. Mol Microbiol 65(6):1568-1581

14. Liu H, Zhang S, Schell MA, Denny TP (2005) Pyramiding unmarked deletions in Ralstonia solanacearum shows that secreted proteins in addition to plant cell-wall-degrading enzymes contribute to virulence. Mol Plant-Microbe Interact 18(12):12961305

15. Milling A, Meng F, Denny TP, Allen C (2009) Interactions with hosts at cool temperatures, not cold tolerance, explain the unique epidemiology of Ralstonia solanacearum race 3 biovar 2 . Phytopathology 99(10):1127-1134

16. Mittenhuber G (2001) Comparative genomics and evolution of genes encoding bacterial (p)ppGpp synthetases/hydrolases (the rel, RelA and SpoT proteins). J Mol Microbiol Biotechnol 3 (4):585-600

17. Nanamiya $H$, Kasai $K$, Nozawa A, Yun CS, Narisawa $T$, Murakami K, Natori Y, Kawamura F, Tozawa Y (2008) Identification and functional analysis of novel (p)ppGpp synthetase genes in Bacillus subtilis. Mol Microbiol 67 (2):291-304

18. Poussier S, Trigalet-Démery D, Vandewalle P, Goffinet B, Luisetti J, Trigalet A (2000) Genetic diversity of Ralstonia solanacearum as assessed by PCR-RFLP of the hrp gene region, AFLP and 16S rRNA sequence analysis, and identification of an African subdivision. Microbiology 146:1679-1692

19. Poussier S, Vandewalle P, Luisetti J (1999) Genetic diversity of African and worldwide strains of Ralstonia solanacearum as determined by PCR-restriction fragment length polymorphism analysis of the hrp gene region. Appl Environ Microbiol 65 (5):2184-2194

20. Roberts DP, Denny TP, Schell MA (1988) Cloning of the egl gene of Pseudomonas solanacearum and analysis of its role in phytopathogenicity. J Bacteriol 170:1445-1451

21. Rudd KE, Bochner BR, Cashel M, Roth JR (1985) Mutations in the spoT gene of Salmonella typhimurium: effects on his operon expression. J Bacteriol 163:534-542

22. Schell MA (2000) Control of virulence and pathogenicity genes of Ralstonia solanacearum by an elaborate sensory network. Annu Rev Phytopathol 38:263-292

23. Semenov AV, van Bruggen AHC, van Overbeek L, Termorshuizen AJ, Semenov AM (2007) Influence of temperature fluctuations on Escherichia coli O157: H7 and Salmonella enterica serovar Typhimurium in cow manure. FEMS Microbiol Ecol 60:419-428

24. Spira B, Hu X, Ferenci T (2008) Strain variation in ppGpp concentration and RpoS levels in laboratory strains of Escherichia coli K-12. Microbiology 154:2887-2895

25. Stevens P, van Elsas JD (2010) A putative genomic island, PGI-1, in Ralstonia solanacearum biovar 2 revealed by subtractive hybridization. Antonie van Leeuwenhoek. doi 10.1007/s10482-010$9450-4$

26. Stevens P, van Elsas JD (2010) Genetic and phenotypic diversity of Ralstonia solanacearum biovar 2 strains obtained from Dutch waterways. Antonie Leeuwenhoek 97:171-188

27. Sun W, Roland KL, Branger CG, Kuang X, Curtiss R (2009) The role of relA and spoT in Yersinia pestis KIM5+ pathogenicity. PLoS ONE 4(8):e6720

28. Tamura K, Dudley J, Nei M, Kumar S (2007) MEGA4: Molecular Evolutionary Genetics Analysis (MEGA) Software Version 4.0. Mol Biol Evol 24(8):1596-1599

29. Teather RM, Wood PJ (1982) Use of Congo red-polysaccharide interactions in enumeration and characterization of cellulolytic bacteria from the bovine rumen. Appl Environ Microbiol 43 (4): $777-780$

30. Tilbeurgh H, van Claeyssens M, De Bruyne CK (1984) The use of 4-methylumbelliferyl and other chromophoric glycosides in the study of cellulolytic enzymes. FEBS Lett 149:152-156

31. Timms-Wilson TM, Bryant K, Bailey MJ (2001) Strain characterization and $16 \mathrm{~S}-23 \mathrm{~S}$ probe development for differentiating geographically dispersed isolates of the phytopathogen Ralstonia solanacearum. Environ Microbiol 3(12):785-797

32. Uzan M, Danchin A (1976) rapid test for RelA mutation in Escherichia coli. Biochem Biophys Res Commun 69(3):751-758

33. Van der Wolf JM, Bonants PJM, Smith JJ, Hagenaar M, Nijhuis E, van Beckhoven JRCM, Saddler GS, Trigalet A, Feuillade R (1998) Genetic diversity of Ralstonia solancaerum race 3 in Western Europe determined by AFLP, RC-PFGE and Rep-PCR. In: Prior PH, Allen C, Elphinstone J (eds) Bacterial wilt disease: molecular and ecological aspects. Springer, Berlin, pp 44-49 
34. Van Elsas JD, Kastelein P, de Vries PM, van Overbeek LS (2001) Effects of ecological factors on the survival and physiology of Ralstonia solanacearum bv. 2 in irrigation water. Can J Microbiol 47(9):842-854

35. Van Elsas JD, Kastelein $P$, van Bekkum $P$, van der Wolf JM, de Vries PM, van Overbeek LS (2000) Survival of Ralstonia solanacearum biovar 2, the causative agent of potato brown rot, in field and microcosm soils in temperate climates. Phytopathology 90(12):1358-1366

36. Van Elsas JD, van Overbeek LS, Bailey MJ, Schönfeld J, Smalla K (2005) Fate of $R$. solanacearum biovar 2 as affected by conditions and soil treatments in temperate climate zones. In:
Allen C, Prior P, Hayward AC (eds) Bacterial wilt disease and the Ralstonia solanacearum species complex. American Phytopathological Society Press, St. Paul, pp 39-49

37. Wendrich TM, Marahiel MA (1997) Cloning and characterization of a relA/spoT homologue from Bacillus subtilis. Mol Microbiol 26:65-79

38. Winstead NN, Kelman A (1952) Inoculation techniques for evaluating resistance to Pseudomonas solanacearum. Phytopathology 42:628-634

39. Yang XM, Ishiguro EE (2003) Temperature-sensitive growth and decreased thermotolerance associated with relA mutations in Escherichia coli. J Bacteriol 185:5765-5771 